\title{
FURTHER STUDY ON TWO-SURFACE MODEL FOR STRUCTURAL STEELS UNDER UNIAXIAL CYCLIC LOADING
}

\author{
C. SHEN*, E. MIZUNO** and T.USAMI***
}

\begin{abstract}
In this paper, a general definition of the accumulated effective plastic strain concept is introduced so that the two-surface model proposed by the authors in Ref. 1) can be extended easily to multiaxial stress state by combining with a proper hardening rule. In the treatment of the bounding line, the ultimate tensile stress is used as the limiting value of the bounding surface radius. In addition, the reduction of the bounding line slope is considered. Finally, the model parameters are calibrated according to the experimental data and presented. The predictions for various kinds of steels with the present model show a good agreement with the experimental results.
\end{abstract}

Keywords: plasticity, two-surface model, cyclic loading, plastic work.

\section{INTRODUCTION}

Following experimental observations, the authors proposed a two-surface model ${ }^{1)}$ for the uniaxial cyclic behavior of steels with yield plateau, such as SS400, SM490 and SM570. In order to extend this uniaxial model to the multiaxial stress state, further modification and refinement have been made in the present paper: firstly, the concept of the accumulated effective plastic strain ${ }^{2}$ (as abbreviated to A.E.P.S.) is generalized to the multiaxial stress state by introducing a surface defined in the plastic strain space; secondly, the bounding surface is assumed to change in size with the plastic deformation but has some limiting value; thirdly, the bounding line slope is assumed to decrease with the plastic work.

\section{EXTENSION OF A.E.P.S. IN MULTIAXIAL STRESS STATE}

The concept of accumulated effective plastic strain (A.E.P.S.) under uniaxial condition in Refs. 1) and 2 ) is defined as the maximum amplitude of plastic strain that the material has ever experienced before and can be written as:

$$
\bar{\varepsilon}^{p}=\varepsilon_{\max }^{p}-\varepsilon_{\min }^{p}
$$

where $\varepsilon_{\max }^{p}$ and $\varepsilon_{\min }^{p}$ represent the arithmetic maximum and minimum values of the axial plastic strain respectively. Extending the concept of A.E.P.S. under the uniaxial case to the multiaxial stress state, a surface defined in the plastic strain space ${ }^{3)}$, called A.E.P.S. surface, is introduced and expressed as follows.

\footnotetext{
${ }^{*}$ Graduate Student, Dept. of Civil Engineering, Nagoya University, Nagoya

${ }^{* *}$ Member of JSCE, Ph.D., Associate Professor, Dept. of Civil Engineering, Nagoya University, Nagoya

*** Member of JSCE, Dr. Eng., D.Sc., Professor, Dept. of Civil Engineering, Nagoya University, Nagoya
}

$$
\phi=\phi\left(\varepsilon_{i j}^{p}\right)=\frac{2}{3}\left(\varepsilon_{i j}^{p}-\eta_{i j}\right)\left(\varepsilon_{i j}^{p}-\eta_{i j}\right)-\rho^{2}=0
$$

where $\varepsilon_{i j}^{p}$ is the component of plastic strain; $\eta_{i j}$ and $\rho$ represent the center and radius of the surface respectively. During the plastic deformation, A.E.P.S. surface moves and changes in size conditionally. According to the definition of A.E.P.S. in the uniaxial case, the motion of A.E.P.S. surface may be defined as follows.

$$
d \eta_{i j}= \begin{cases}\frac{1}{2} d \varepsilon_{i j}^{p} & \text { if } \phi\left(\varepsilon_{i j}^{p}+d \varepsilon_{i j}^{p}\right)>0 \\ 0 & \text { otherwise }\end{cases}
$$

From the condition $d \phi=0$, there exists:

$$
\frac{2}{3}\left(\varepsilon_{i j}^{p}-\eta_{i j}\right)\left(d \varepsilon_{i j}^{p}-d \eta_{i j}\right)-\rho d \rho=0
$$

Then substituting Eq.(3) into Eq.(4) yields:

$$
d \rho= \begin{cases}\frac{1}{3}\left(\varepsilon_{i j}^{p}-\eta_{i j}\right) d \varepsilon_{i j}^{p} / \rho & \text { if } \phi\left(\varepsilon_{i j}^{p}+d \varepsilon_{i j}^{p}\right)>0 \\ 0 & \text { otherwise }\end{cases}
$$

It can be seen that, in the uniaxial case, $\rho$ is one half of A.E.P.S. $\bar{\varepsilon}^{p}$. Therefore, the equations in Ref. 1) related to A.E.P.S., such as the equations to calculate the elastic range and the reduction of the yield plateau, can also be used in the multiaxial stress state by replacing $\bar{\varepsilon}^{p}$ with $2 \rho$.

\section{RADIUS OF BOUNDING SURFACE}

In Ref. 1), the heights of two bounding lines in tension and compression sides were assumed to change with A.E.P.S. linearly(i.e., Eq.(10) in Ref. 1)). However, since the bounding lines will become the bounding surface in the multiaxial stress state, it is important to know the radius of the bounding surface. Moreover, it is observed that the stress-strain 


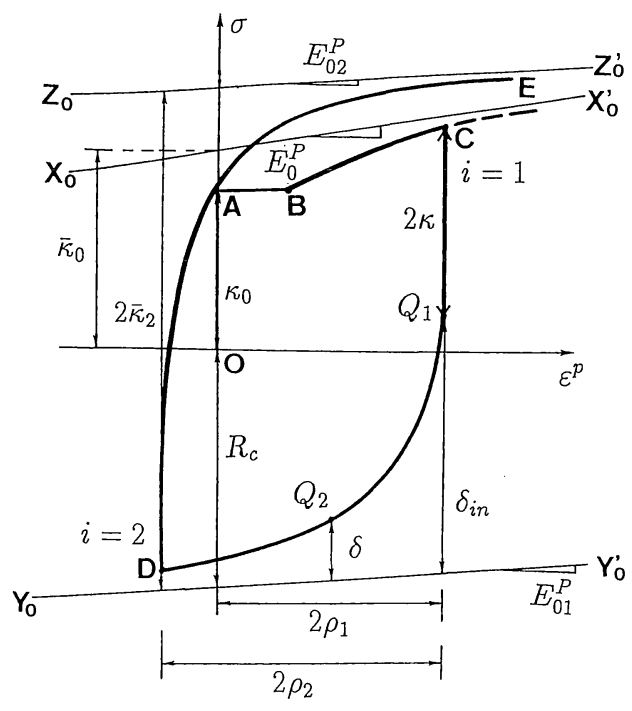

Fig. 1 Axial Stress $\sigma$ and Plastic Strain $\varepsilon^{p}$ Curve in One Cycle Loading Experiment

curve will reach a saturated state with the increase of plastic deformation under the cyclic loading. In this paper, the radius $\bar{\kappa}_{i}$ of the bounding surface for the loading path between the ith and the $(i+1)$ th reversed loading points is assumed to follow

$$
\bar{\kappa}_{i}=\bar{\kappa}_{\infty}+\left(\bar{\kappa}_{0}-\bar{\kappa}_{\infty}\right) \exp \left(-\zeta \rho_{i}^{2}\right)
$$

where $\bar{\kappa}_{0}$ is the radius of the initial bounding surface(denoted by R in Ref. 1)); $\bar{\kappa}_{\infty}$ is the limiting value of the bounding surface radius and defined to be equal to the ultimate tensile stress $\sigma_{u} ; \rho_{i}$ represents one half of A.E.P.S. at the ith reversed loading point(in Fig. $1, i=1$ for point $\mathrm{C}$ and $i=2$ for point $\mathrm{D})$ and $\zeta$ is a constant. The parameters $\bar{\kappa}_{0}$ and $\zeta$ are determined from one cycle loading curve, which spans both the tensile and compressive plastic strain, as schematically shown in Fig. 1(i.e., loading type (3) in Ref. 1)), in which about $5 \%$ A.E.P.S. is required to get a stable state. As shown in Fig. 1, the bounding lines for loading paths $\mathrm{CD}$ and $\mathrm{DE}$ are supposed to be $Y_{0} Y_{0}^{\prime}$ and $Z_{0} Z_{0}^{\prime}$ respectively. Then, the radii of the bounding surfaces for these two loading paths are obtained to be $\bar{\kappa}_{1}$ and $\bar{\kappa}_{2}$ respectively, where $\bar{\kappa}_{1}=\frac{1}{2}\left(\bar{\kappa}_{0}+R_{c}\right) ; R_{c}$ is the height of the bounding line $Y_{0} Y_{0}^{\prime}$ from the origin point $\mathrm{O}$ (see Fig. 1) and $\bar{\kappa}_{2}$ is the half distance between $Z_{0} Z_{0}^{\prime}$ and $Y_{0} Y_{0}^{\prime}$ along the stress axis. Substituting these conditions into Eq.(6) and solving the following nonlinear equations,

$$
\left\{\begin{array}{cl}
\frac{1}{2}\left(\bar{\kappa}_{0}+R_{c}\right) & =\bar{\kappa}_{\infty}+\left(\bar{\kappa}_{0}-\bar{\kappa}_{\infty}\right) \exp \left(-\zeta \rho_{1}^{2}\right) \\
\bar{\kappa}_{2} & =\bar{\kappa}_{\infty}+\left(\bar{\kappa}_{0}-\bar{\kappa}_{\infty}\right) \exp \left(-\zeta \rho_{2}^{2}\right)
\end{array}\right.
$$

the parameters $\bar{\kappa}_{0}$ and $\zeta$ for various steels are ob- tained and presented in Table 1.

It should be noted that the size of the bounding surface is assumed to be constant during one loading path and changes only at the reversed loading points(i.e., C and D in Fig.1).

\section{SLOPE OF BOUNDING LINE}

The slope of the bounding line is usually assumed to be constant throughout the whole loading history in the existing two-surface models ${ }^{4), 5}$. However, it has been observed in the cyclic loading experiments that the slope of the bounding line decreases with the increase in loading cycles and approaches a limiting value of zero. Under the previous assumption that the slope of the bounding line dose not change during the whole loading history in the model prediction, an accurate prediction has not been obtained, especially for the large plastic strain(say, larger than $5 \%)$. In the present paper, therefore, the slope of the bounding line is supposed to decrease with the plastic work and expressed as follows.

$$
E_{0 i}^{P}=\frac{E_{0}^{P}}{1+\omega W_{i}^{P}}
$$

where $E_{0 i}^{P}$ represents the slope of bounding line for the loading path between the ith and the $(i+1)$ th reversed loading points; $W_{i}^{P}$ is the plastic work accumulated from the beginning(i.e., point $\mathrm{O}$ in Fig.1) until the ith reversed loading point; $\omega$ is a constant; $E_{0}^{P}$ indicates the slope of initial bounding line, which is determined by using a monotonic loading curve up to approximately $5 \%$ plastic strain and the size of the initial bounding surface, $\bar{\kappa}_{0}$. On the other hand, the slope $E_{02}^{P}$ of the bounding line $Z_{0} Z_{0}^{\prime}$ and the plastic work $W_{2}^{P}$ accumulated till point $\mathrm{D}$ can be obtained from the stress and plastic strain curve as shown in Fig. 1. By substituting $E_{0}^{P}, E_{02}^{P}$ and $W_{2}^{P}$ into Eq.(8), the parameter $\omega$ is thus determined.

Similar to the case of bounding surface radius $\bar{\kappa}_{i}, E_{0 i}^{P}$ is also assumed to be constant for one loading path. Therefore, the relationship between stress $\sigma$, plastic strain $\varepsilon^{p}$ and distance $\delta$ from the current loading point to the bounding line can be obtained by replacing $E_{0}^{P}$ with $E_{0 i}^{P}$ in Eqs. (2), (3), (4) and (5) in Ref. 1).

In the calibration of the model parameters, especially the bounding line slope, it is generally difficult to obtain the suitable values at one time because of the different personal evaluation. It has been found that the bounding line slope affects the prediction very much when the loading point lies near the bounding line. Therefore, several sets of the parameter values were tried to predict the one cycle loading curve and the best set was picked up.

In order to determine the model parameters, the slope of bounding line $Z_{0} Z_{0}^{\prime}, E_{02}^{P}$, should be first evaluated from one cycle loading curve, that is, a stable 


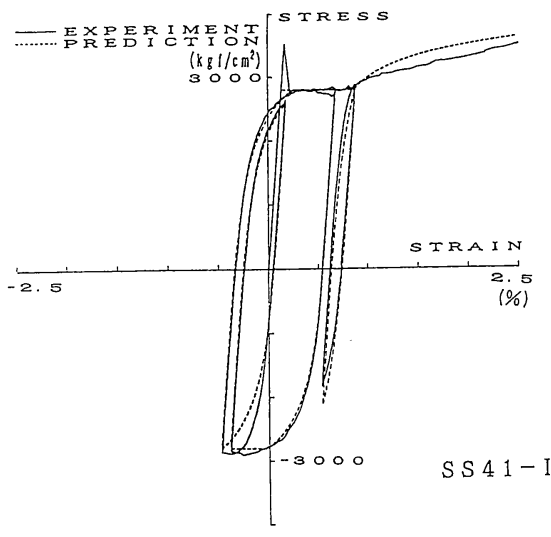

(a) The example of steel SS400

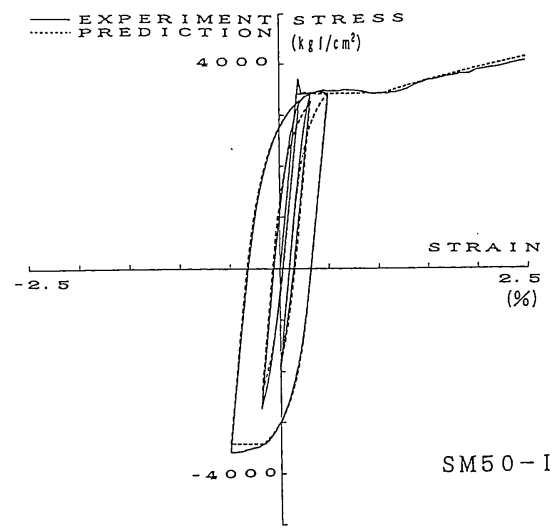

(b) The example of steel SM490

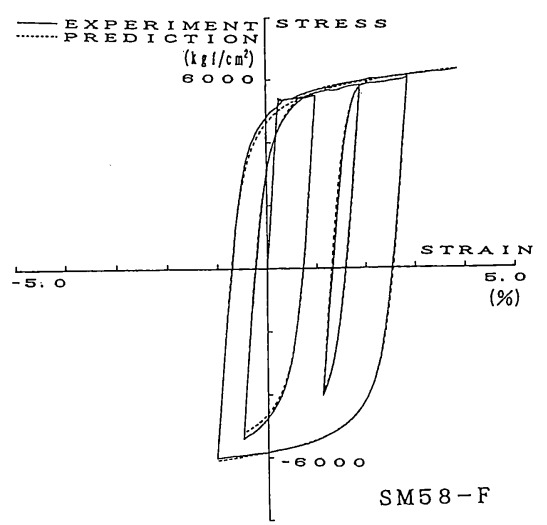

(c) The example of steel SM570

Fig. 2 The Comparison between Experiment and Prediction by the Present Model

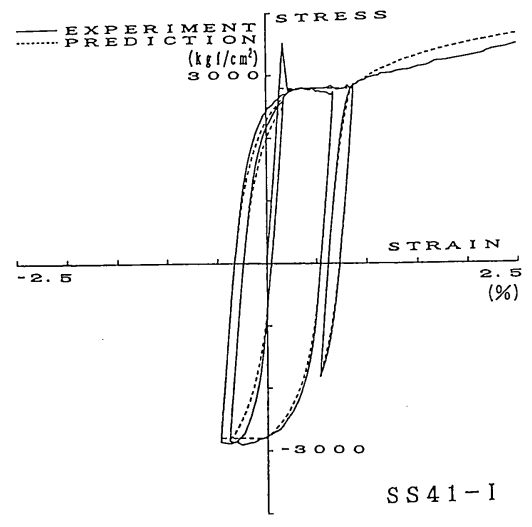

(a) The example of steel SS400

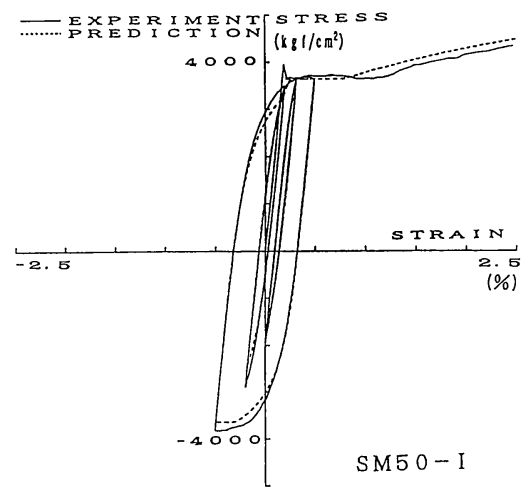

(b) The example of steel SM490

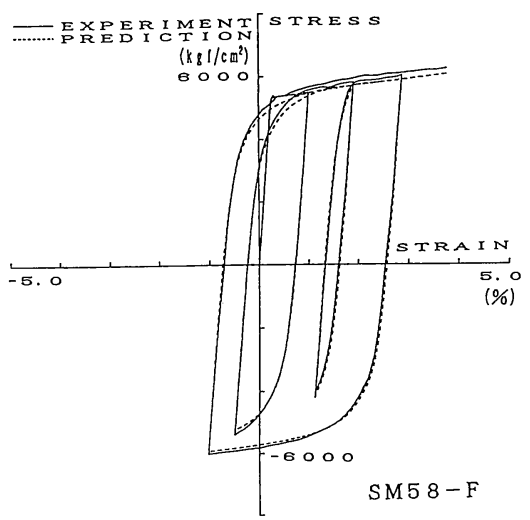

(c) The example of steel SM570

Fig. 3 The Comparison between Experiment and Prediction by the Previous Model 
Table 1 The parameters of steels SS400, SM490 and SM570 in the present model

\begin{tabular}{|c|l|l|l|}
\hline material & $\mathrm{SS} 400$ & $\mathrm{SM} 490$ & $\mathrm{SM} 570$ \\
\hline $\mathrm{E}\left(\mathrm{kgf} / \mathrm{cm}^{2}\right)$ & $2.11 \times 10^{6}$ & $2.10 \times 10^{6}$ & $2.20 \times 10^{6}$ \\
$\sigma_{y}\left(\mathrm{kgf} / \mathrm{cm}^{2}\right)$ & $2.80 \times 10^{3}$ & $3.64 \times 10^{3}$ & $5.35 \times 10^{3}$ \\
$\mathrm{E}_{s t}^{p} / \mathrm{E}$ & $2.49 \times 10^{-2}$ & $3.40 \times 10^{-2}$ & $1.02 \times 10^{-2}$ \\
\hline $\mathrm{E}_{0}^{p} / \mathrm{E}$ & $8.96 \times 10^{-3}$ & $1.01 \times 10^{-2}$ & $7.85 \times 10^{-3}$ \\
$\omega \cdot \sigma_{y}$ & 3.08 & 4.0 & 2.67 \\
\hline $\bar{\kappa}_{0} / \sigma_{y}$ & 1.15 & 1.13 & 1.06 \\
$\sigma_{u} / \sigma_{y}$ & 1.81 & 1.61 & 1.22 \\
$\zeta \cdot \varepsilon_{y}^{2}$ & $9.89 \times 10^{-4}$ & $1.52 \times 10^{-3}$ & $8.04 \times 10^{-3}$ \\
\hline
\end{tabular}

Note: (1) $\bar{\kappa}_{\infty}=\sigma_{u}$ is the limiting value of the bounding surface radius; (2) $\varepsilon_{y}$ is the strain at the initial yield point, i.e., $\varepsilon_{y}=\sigma_{y} / E$; (3) see Table 2 in Ref. 1) for the other parameters.

stress-plastic strain loading curve up to $5 \%$ in tension side(DE in Fig. 1). As for the compression part, i.e., CD in Fig. 1, it is difficult to evaluate the bounding line $Y_{0} Y_{0}^{\prime}$ because of a possible occurrence of buckling and therefore the same slope of the bounding line $Z_{0} Z_{0}^{\prime}$ as in tension part is assumed in the determination of the model parameters.

\section{EXAMPLES}

In the uniaxial case, the present model is the same as the previous one except the calculation of the bounding surface radius and the slope of the bounding line. The present model is applied to predict the uniaxial cyclic experiment for steels SS400, SM490 and SM570. The comparison between the experiment and the prediction by the present model is shown in Fig. 2. At the same time, the prediction by the previously proposed model is shown in Fig. 3 for the same experiments. It can be seen that the prediction by the present model is accurate enough even for the yield plateau.

\section{SUMMARY AND CONCLUSIONS}

From the present study, it can be concluded that: (1) With the introduction of A.E.P.S. surface, the present uniaxial two-surface model can be easily extended to the multiaxial stress state.

(2) By considering reduction of the bounding line slope, the present model is more accurate, especially when the plastic strain is relatively large.

(3) The assumption that the radius of bounding line changes with plastic deformation and limits to the ultimate stress $\sigma_{u}$ is in accord with the experimental results. Moreover, Eq.( $(\dot{6})$ is convenient in the case of multiaxial stress state.

The present model can be extended to the multiaxial stress state easily and will be presented in a different paper. The parameters newly introduced in the present model, such as $\omega, \zeta, \bar{\kappa}_{0}$ and $\bar{\kappa}_{\infty}$, are simply and clearly determined without increasing the experiment work.

\section{REFERENCES}

1) Shen C., Tanaka, Y., Mizuno, E. and Usami T.: A two-surface model for steels with yield plateau, Proc. of JSCE, Structural Eng./Earthquake Eng. Vol.8, No.4, 179s-188s, Jan. 1992.

2) Minagawa, M., Nishiwaki, T. and Masuda, N.: Modelling cyclic plasticity of structural steels, Structural Eng./Earthquake Eng., Vol.4, No.2, pp.361-370, Oct., 1987.

3) Ohno, N. and Kachi Y.: A constitutive model of cyclic plasticity for nonhardening material, Trans. of ASME, J. of Applied Mechanics, Vol.53, pp395-403, June, 1986.

4) Dafalias, Y.F. and Popov, E.P.: A model of nonlinear hardening materials for complex loading, Acta, Mech., Vol.21, pp.173-192, 1975.

5) Tseng, N.T. and Lee, G.C.: Simple plasticity model of two-surface type, Journal of Engineering Mechanics, Proc. ASCE, Vol.109, NO.3, pp.795-810, June 1983.

(Received May 18, 1992)

一軸繰り返乙荷重を受ける構造用鋼素材の二曲面モデルス 関寸る補足的研究

$$
\text { 沈 赤・水野英二・宇佐美勉 }
$$

本論文では、文献 1)において著者らが提案した二曲面モデルを多軸応力状態に容易 飞拡張するてとができるように累積相当塑性ひずぬの一般的な定義を導入した。境界 線に対しては、銅素材の引張極限応力を境界曲面の限界値とし、さらに、境界線の勾 配は塑性仕事量により低隇すると仮定した。モデルバラメータの決定法について説明 し、鋼素材 SS400,SM490,SM570 K対するパラメータ值を示した。本提案モデルKよ るとれら鋼素材の予測結果と実験データとを比較し、モデルの有効性を検討した。 